\section{Clinico-Pathological Analysis of Osteomyelitis in Cancrum Oris (Noma) Patients Seen in Noma Children Hospital, Northwest Nigeria}

Bala MUJTABA, Chukwuma Benedict CHIMEZIE, Aremu Ibikunle ADEBAYO, Abdurrazaq Olanrewaju TAIWO, Godwin Ugochukwu NDUBUIZU, Abubakar Sadeeq FAWA.

[Department of Dental and Maxillofacial Surgery, Usmanu Danfodiyo University Teaching Hospital PMB 2370, Sokoto, Nigeria]

\author{
Correspondence \\ Dr. Bala Mujtaba \\ Department of Dental and Maxillofacial Surgery, \\ Usmanu Danfodiyo University Teaching Hospital \\ PMB 2370, Sokoto, Nigeria \\ Email: cdcsokoto456@gmail.com
}

\section{ABSTRACT}

Background: Cancrum oris is a rapid and devastating infectious disease of the orofacial region, which can be life threatening in its fulminant stage. Infection of bone (osteomyelitis) is a possible sequelae of Noma (cancrum oris) and is more likely due to late presentation especially in our environment. A literature search revealed scanty research describing osteomyelitis in Noma patients.

Objective: To analyze the clinico-pathology of osteomyelitis in Noma patients diagnosed and treated at Noma Children Hospital, Sokoto.

Methods: The design was a 2-year retrospective study of records of Thirty-two patients who had sequestrectomy secondary to osteomyelitis in Noma (Cancrum oris). Age, gender, jaws affected and side of involvement were analyzed

Results: The age ranged from 2-11 years with mean \pm standard deviation $5.47 \pm 2.68$ years was recorded. Osteomyelitis in Noma patients was found among 17 (53.10\%) males compared to 15 (46.90\%) females. In 20 (62. $50 \%$ ) of the cases, anterior maxillary involvement was observed and the remaining 12 (37. 50\%) was found at the mandibular posterior region and it is more common on the left side. Result of histopathology showed both acute and chronic inflammatory cells. Necrosis and bone hyperactivity was observed in most of the slides.

Conclusion: Osteomyelitis is a common complication of Noma and its treatment is of paramount importance for adequate management of Noma patients.

Keywords: Noma, Osteomyelitis, Sequestrectomy, Malnutrition

Received: 13 Sept, 2021

Revision: 5 Nov, 2021

Accepted: 5 Nov, 2021

https://orcid.org/

Citation: Mujtaba B, Chimezie CB, Adebayo AI, Taiwo AO, Ndubuizu GU, Fawa AS. Clinico-Pathological Analysis of Osteomyelitis in Cancrum Oris (Noma) Patients Seen in Noma Children Hospital, Northwest Nigeria. Nig J Dent Res 2022; 7(1):29-34 


\section{Introduction}

Cancrum oris (Noma) is a rapidly progressive gangrenous tissue infection of the orofacial region, which often results in severe soft and bony tissue loss with severe debilitating consequences. ${ }^{1,2}$ It was first described by Carlous Barthus in 1595 and has been described as overwhelming microbial invasion of the oral cavity which often lead to gangrenous lesions on the face that can extend to involve even the nose and ears in some extreme cases. ${ }^{3}$ Some described Noma as necrotizing fasciitis-like wound. ${ }^{4} \mid \mathrm{t}$ was common in Europe and America in previous centuries but disappeared and reappeared during World War II predominantly in Netherland due to severe food shortage. Today Noma is seen mostly in Africa, some parts of Asia and Latin America. In Africa, Noma has been commonest in some parts of the East and West African countries. ${ }^{5,6}$ Children are typically affected, although some cases among adults have been reported. ${ }^{7}$ Malnutritrion, poor oral hygiene and some diseases such as measles, chronic malaria, tuberculosis, and HIV are some of the key predisposing factors. Mortality rates as high as $90 \%$ have been reported. ${ }^{6,7}$ Its quickly spreading nature makes the facial bones vulnerable to involvement and osteomyelitis has been identified as a possible sequelae. $^{8}$ The bone involvement in form of osteomyelitis has been largely ignored in the scientific literature. Hence this study highlighted the pattern of osteomyelitis in cancrum oris patients treated at Noma Children Hospital, Sokoto. Therefore, the aim of this study was to highlight the clinico-pathological pattern of osteomyelitis in Noma patients.

\section{Materials and methods}

Ethical clearance was obtained from the department of planning, research and statistics, ministry of health Sokoto state with reference number $\mathrm{SMH} / 1580 / \mathrm{V} . \mathrm{IV}$

A retrospective study of Noma patients managed on account of osteomyelitis secondary to cancrum oris at the Noma Children Hospital, Sokoto, Nigeria, over a period of 2 years (from March, 2018 to April 2020) was done. Thirty two patients' case notes that underwent sequestrectomy were retrieved. Age, gender, jaws involvement, side affected and teeth involvement were recorded. Results of histopathology of all the thirty two patients were also noted. Data was entered into Statistical package for social sciences (IBM-SPSS) version 21.0 for analysis. Results were presented in tables and figures and expressed as mean $( \pm S D)$.

\section{Results}

We analyzed a total of 32 patients who were in the age range of 2-11 years with mean \pm standard deviation of $5.47 \pm 2.68$ years (Table 1 ). Osteomyelitis in Noma patients was found in $17(53.10 \%)$ males compared to $15(46.90 \%)$ females (Figure 1 ). In 20 (62. $50 \%$ ) of the cases, we observed anterior maxillary involvement and the remaining 12 (37. $50 \%$ ) in posterior mandible (Figure 2, Table 2). This study did not find any mandibular anterior involvement. Noma associated osteomyelitis occurred more commonly on the left side, accounting for $62 \%$ of the cases (Fig 3). Maxillary deciduous were the commonest teeth affected (Table 2). Figure 4 is a clinical photograph of a Noma patient with osteomyelitis of the jaws. Result of histopathology showed both acute and chronic inflammatory cells. Necrosis and bone hyperactivity was observed in most of the slides. Sequestrectomy was done under GA for all cases prior to flap surgeries. Microscopy, culture and sensitivity (MCS) was done in only 8 cases and revealed no growth of microorganism.

Table 1: Frequency of age involvement of osteomyelitis in Noma patients

\begin{tabular}{|l|l|}
\hline Age (years) & $\mathrm{n}(\%)$ \\
\hline 2.00 & $6(18.8)$ \\
\hline 3.00 & $4(12.5)$ \\
\hline 4.00 & $1(3.1)$ \\
\hline 5.00 & $5(15.6)$ \\
\hline 6.00 & $6(18.8)$ \\
\hline 7.00 & $2(6.3)$ \\
\hline 8.00 & $3(9.4)$ \\
\hline 9.00 & $2(6.3)$ \\
\hline 10.00 & $2(6.3)$ \\
\hline 11.00 & $1(3.1)$ \\
\hline Total & $32(100)$ \\
\hline
\end{tabular}

-Range of 2-11 years

-Mean \pm standard deviation of $5.47 \pm 2.68$ years 


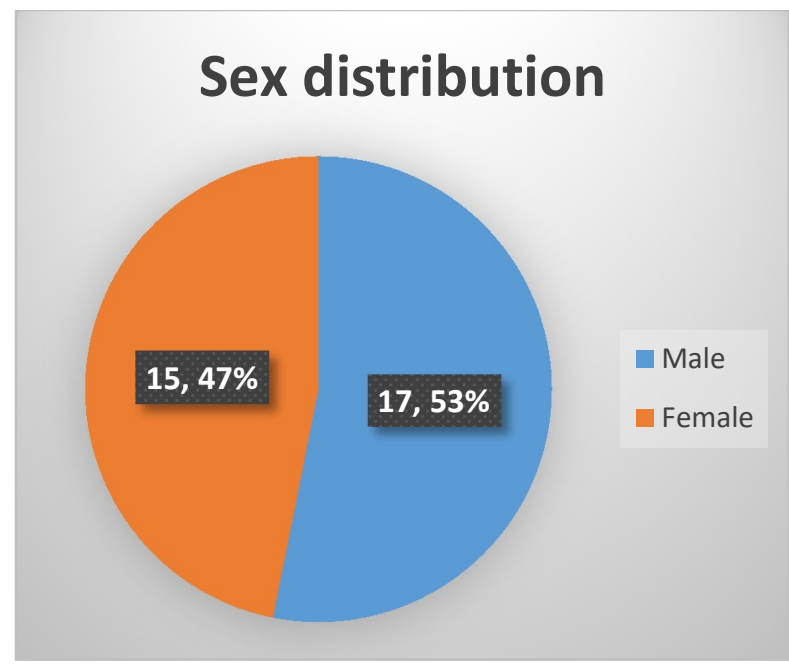

Figure 1: Sex distribution of subjects in the study population.

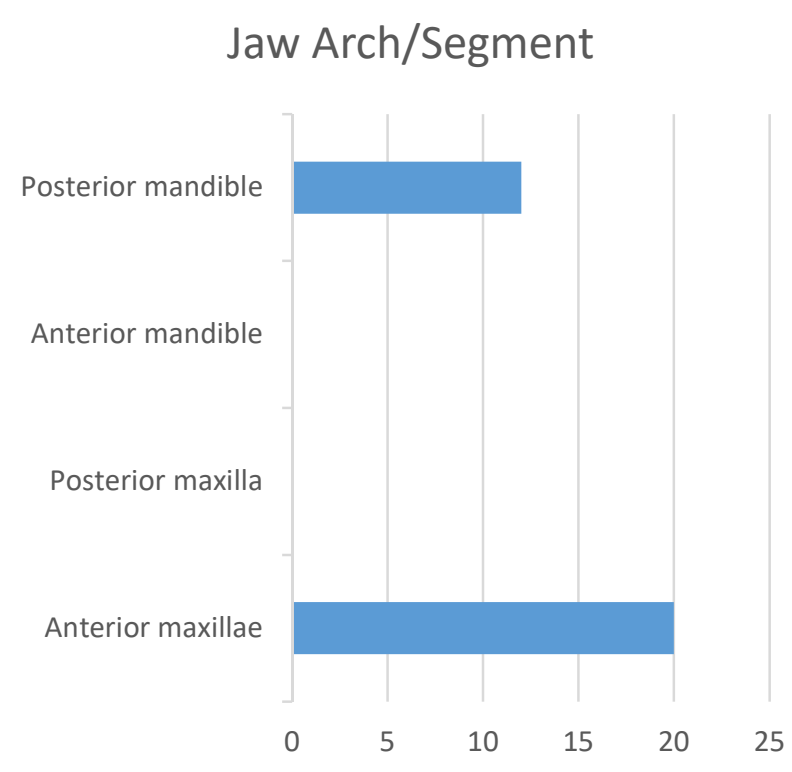

\section{osteomyelitis affected side}

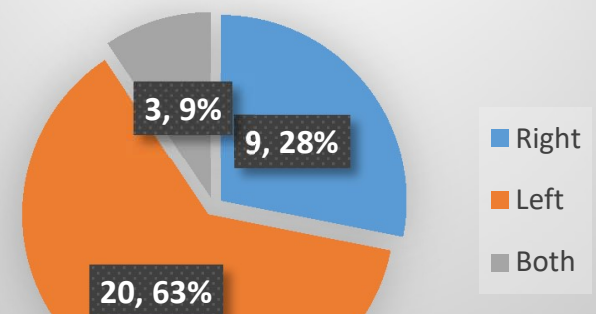

Figure 3: Side of osteomyelitis among the study subjects.

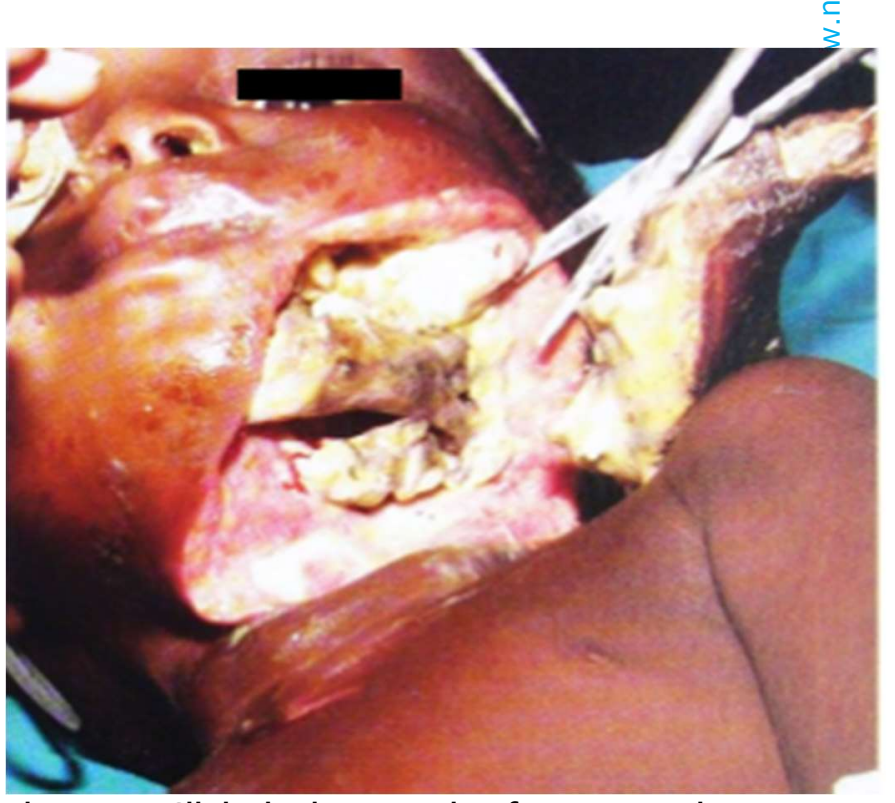

Figure 4: Clinical photograph of Noma patient showing osteomyelitis of the jaw.

Figure 2: Jaw arch/segment involved among the study subjects 
Table 2: Pattern of occurrence of osteomyelitis in Noma

\begin{tabular}{|c|c|c|c|c|c|}
\hline AGE (years) & SEX & Fathers occupation & REGION & Teeth affected & Side \\
\hline 2 & $\mathrm{M}$ & Farming & post.mandible & $\mathrm{D}$ & Right \\
\hline 10 & $\mathrm{~F}$ & Farming & ant.maxilla & DE6 & Left \\
\hline 5 & $\mathrm{M}$ & Farming & ant.maxilla & $A B C$ & Left \\
\hline 4 & $M$ & Farming & ant.maxilla & AA & Both \\
\hline 2 & $\mathrm{~F}$ & Farming & post.mandible & $6 \mathrm{D}$ & Left \\
\hline 6 & $M$ & Farming & ant.maxilla & $1 B$ & Left \\
\hline 6 & $\mathrm{~F}$ & business & ant.maxilla & $\mathrm{BC}$ & Left \\
\hline 8 & $M$ & Farming & post.mandible & DE6 & Left \\
\hline 7 & $\mathrm{M}$ & Farming & ant.maxilla & $\mathrm{AAB}$ & Both \\
\hline 6 & $\mathrm{~F}$ & Farming & ant.maxilla & $A B C$ & Left \\
\hline 6 & $\mathrm{~F}$ & Farming & post.mandible & $\mathrm{DE}$ & Left \\
\hline 5 & $\mathrm{~F}$ & Farming & ant.maxilla & A & Right \\
\hline 5 & $\mathrm{~F}$ & Farming & ant.maxilla & $A B C$ & Right \\
\hline 6 & $\mathrm{~F}$ & Rearing & ant.maxilla & $A B C$ & Right \\
\hline 9 & $\mathrm{M}$ & Farming & ant.maxilla & $A B$ & Right \\
\hline 6 & $\mathrm{M}$ & Farming & ant.maxilla & $A$ & Left \\
\hline 11 & $M$ & Farming & ant.maxilla & $A B$ & Right \\
\hline 3 & $\mathrm{M}$ & Farming & ant.maxilla & $A B$ & Left \\
\hline 8 & $M$ & Farming & post.mandible & DE & Left \\
\hline 2 & $\mathrm{~F}$ & business & ant.maxilla & $A B$ & Left \\
\hline 3 & $\mathrm{~F}$ & Rearing & post.mandible & $D$ & Left \\
\hline 2 & $\mathrm{~F}$ & Farming & post.mandible & E6 & Right \\
\hline 9 & $\mathrm{M}$ & Farming & ant.maxilla & $1 \mathrm{~B}$ & Left \\
\hline 7 & M & Farming & ant.maxilla & $\mathrm{BC}$ & Right \\
\hline 10 & $\mathrm{M}$ & Farming & post.mandible & DE6 & Left \\
\hline 2 & $\mathrm{~F}$ & Farming & post.mandible & $D$ & Left \\
\hline 8 & $\mathrm{~F}$ & Farming & ant.maxilla & $A B$ & Left \\
\hline 2 & $M$ & Farming & ant.maxilla & $A B C$ & Left \\
\hline 3 & $\mathrm{~F}$ & Farming & post.mandible & $D$ & Left \\
\hline 3 & $\mathrm{M}$ & Farming & ant.maxilla & $\mathrm{ABAB}$ & Both \\
\hline 5 & $M$ & Farming & post.mandible & $\mathrm{DE}$ & Left \\
\hline 5 & $\mathrm{~F}$ & Farming & post.mandible & $\mathrm{DE}$ & Right \\
\hline
\end{tabular}

A - Deciduous central incisor

B - Deciduous lateral incisor

C - Deciduous canine

D - Deciduous first molar

E - Deciduous second molar

1-Permanent central incisor

6 - Permanent first molar

\section{Discussion}

This study has shown Noma as a disease occurring at an age range of 2-11 years and this is different from reports in the literatures. Enwonwu et al. ${ }^{8}$ reported ant. - Anterior

post. - Posterior that Noma occurs between the age range of 1-4 years which according to them is a coincidental period of linear growth retardation. Leila MS observed an age range of 2-7years. ${ }^{9}$ Just like the current study, Elise $S$ Farley et al. ${ }^{10}$ conducted a study on Cancrum Oris patients in the same hospital and found out that, $34.3 \%$ of the patients were older than 15 years at admission, with an age range (during follow-up) of 4 -50 years. This disparity in age might be due to lack of basic immunizations and the largely present predisposing factors in our environment. 
The sequelae of Noma depend significantly on the site affected, extent and severity of tissue destruction. ${ }^{11,12}$ These sequelae include osteomyelitis among others such as trismus, bony fusion, and intense scaring. ${ }^{13,14,15}$ This study majorly targeted osteomyelitis as a common sequela of Noma that has been ignored in most of the Noma literatures. We observed that osteomyelitis is a common sequelae of chronic Noma and that it is more common in male patients. Maxillary anterior region is more commonly involved, and this is different from the conventional osteomyelitis that is far more common in the mandibular posterior region. ${ }^{16,17}$, Several authors have reported maxillary involvement as the rarest site for osteomyelitis. ${ }^{17,}{ }^{18}$ Our contrary finding might be due to the pattern of spread and extensive tissue destruction in Noma.

The histopathological examination showed dead bone surrounded by bone cells and inflammatory cells infiltration ranging from inflammatory exudates composed of polymorphonuclear leukocyte and macrophages to a predominant lymphocytic and plasma cell infiltration. Necrosis and high level of bone reactivity was seen in most of the slides. Although the histopathological features of osteomyelitis in Noma patients did not differ significantly from the conventional osteomyelitis, the high reactivity of bone seen is related to the younger age of occurrence of Noma.

Microscopy culture and sensitivity (MCS) was done in only eight cases of the total of the patients because of our resource limited environment. No growth of microorganisms was observed in any of the eight cases. This observation may be because microorganisms associated with cancrum oris are majorly anaerobes.

The management of the Noma defect involves careful attention to hard and soft tissues. Most of the time surgeons reconstruct the soft tissue defect and might have neglected the bone destroyed by osteomyelitis. The principle is that sequestrum is removed if loose or allowed to remain in the hope that involucrum (new bone) will form around it. ${ }^{18}$ It is also followed up until complete debridement before reconstruction.

\section{Conclusion}

Noma is a rapidly spreading gangrenous stomatitis that has been known to destroy bone. Osteomyelitis has been demonstrated in this study as a common complication. For adequate management of Noma patients, treatment of osteomyelitis is of paramount importance.

\section{Financial support and sponsorship}

Nil

\section{Conflict of interest}

None Declared.

\section{References}

1. Tonna JE, Lewin MR, Mensh B. A case and review of Noma. PLoS Negl Trop Dis. 2010; 4:e869.

2. Tempest MN. Cancrum oris. Br J Surg. 1966; 53: 949-69.

3. Ibikunle AA, Semiyu AA, Taiwo $A O$ et al. Management of 159 cases of acute canrum oris: Our experience at the Noma children hospital,Sokoto Arch Med Health Sci. 2017; 5:172-6

4. Adeola DS, Eguma SA, Ononiwu CN. Cancrum oris among Nigerian children. Niger J Surg Res. 2004; 6:1-2.

5. Adeola DS, Obiadazie AC. Protocol for managing acute cancrum oris in children; an experience in five cases. Afr J pediatr Surg. 2009; 6:77-81.

6. Chidzonga MM, Mahomva L. Noma (cancrum oris) in human immunodeficiency virus infection and acquired immunodeficiency syndrome (HIV and AIDS): Clinical experience in Zimbabwe. J Oral Maxillofac Surg. 2008; 66: 475-85.

7. Oche MO, Umar AS, Ibrahim MT, Sabitu K. An assessment of the impact of health education on maternal knowledge and practice of childhood immunization in Kware, Sokoto State. J Public Health Epidemiol. 2011; 3:440-7.

8. Enwonwu CO. Noma: A neglected scourge of children in sub-Saharan Africa. Bull World Health Organ. 1995; 73:541-5.

9. Leila MS, Klass M, Denise B.M. Noma: Overview of neglected disease and human right violation. Am. Trop. Med. Hyg. 2017; 92: 268-278.

10. Elise SF, Mohana A, Taiwo AO et al. Outcomes at 18 mo of 37 Noma (cancrum oris) cases surgically treated at the Noma Children's Hospital, Sokoto, Nigeria. Trans R Soc Trop Med Hyg. 2020; 114: 812-819. 
11. Reddy BP, Reddy BS, Kiran G, Chembolu N. Cancrum oris: A devastating orofacial gangrene. J Dr NTR Univ Health Sci. 2012; 1: 192.

12. Marck KW. A history of Noma: The "Face of Poverty". Plast Reconstr Surg. 2003; 111:1702-7.

13. Barrios TJ, Aria AA, Brahney C. Cancrum oris in a HIV-positive patient. J Oral Maxillofac Surg. 1995; 53:851-5.

14. Braimah RO, Aremu A, Taiwo AO et al. Risk factors and mortality rate of acute cancrum oris (Noma) in Sokoto North-West Nigeria: A 13-year survey. J. Pediatr. Dent. 2017; 1:p.1

15. Oginni FO, Oginni AO, Ugboko VI, Otuyemi OD. A survey of cases of cancrum oris seen in lle-Ife, Nigeria. Int J Paediatr Dent 1999; 9:75-80.
16. Urade M, Noguchi K, Takaoka K, Moridera K, Kishimoto $\mathrm{H}$. Diffuse sclerosing osteomyelitis of the mandible successfully treated with pamidronate: a longterm follow-up report. Oral Surg Oral Med Oral Pathol Oral Radiol. 2012. 114: 9-12.

17. Nezafati S, Ghavimi MA, Yavari AS. Localized osteomyelitis of the mandible secondary to dental treatment: report of a case. J Dent Res Dent Clin Dent Prospects. 2009; 3: 67-69.

18. Kaiser D, Bolt I, Hofer M, Relly C, Berthet G, Bolz $D$, et al. Pediatr Chronic nonbacterial osteomyelitis in children: a retrospective multicenter study. Rheumatol Online J. 2015; 13: 25. 